\section{Revista Brasileira de Administração Científica}

Brazilian Journal of Scientific Administration

Abr a Jun 2021 - v.12 - n.2

\title{
O Ministério Público como ombudsman de políticas públicas
}

Este artigo investiga o papel do Ministério Público na fiscalização de políticas públicas. O Ministério Público é instituição permanente, essencial à função jurisdicional do Estado, que exerce atualmente um grande protagonismo na sociedade brasileira. Esta realidade é relativamente recente, haja vista que, com a Constituição de 1988, o Ministério Público foi profundamente transformado. Antes de 1988, o órgão era responsável, basicamente, pela persecução criminal em juízo. Ao longo da década de 1980, o Parquet recebeu novas atribuições, entre as quais a de fiscalização de políticas públicas, ganhando um design institucional único no mundo. O presente estudo tem como objetivo geral a descrição desta nova atribuição de controle de políticas públicas. Para atingi-lo, será descrita a trajetória de empoderamento, bem como as atribuições do Ministério Público na fiscalização de políticas públicas e os instrum entos de que a instituição dispõe para o cumprimento desta tarefa fiscalizatória, como a ação civil pública, o inquérito civil, o compromisso de ajustamento de conduta, a recomendação e a audiência pública. Como metodologia, foi empregada a análise de conteúdo de textos científicos, bem como de leis, propostas legislativas, autos de processos judiciais e de procedimentos extrajudiciais.

Palavras-chave: Ministério Público; Política Pública; Controle da Administração Pública.

\section{The Office of Public Prosecutor as public policy ombudsman}

This article investigates the role of the Office of Public Prosecutor in the inspection of public policies. The Office of Public Prosecutor is a permanent institution essential to the jurisdictional function of the State, which currently plays a major role in Brazilian society. This reality is relatively recent, given that, with the 1988 Constitution, the Office of Public Prosecutor was deeply transformed. Before 1988, the agency was primarily responsible for criminal prosecution in court. Throughout the 1980s, Parquet received new assignments, including that of public policy enforcement, gaining a unique institutional design in the world. The present study has as general objective the description of this new attribution of control of public policies. To achieve this, the trajectory of empowerment will be described, as well as the powers of the Public Prosecutor in the inspection of public policies and the instruments available to the institution to carry out this inspection task, such as public civil action, civil inquiry, conduct adjustment commitment, recommendation and public hearing. As a methodology, content analysis of scientific texts and of laws, legislative proposals, court proceedings and extrajudicial procedures were used.

Keywords: Office of Public Prosecutor; Public Policy; Control of Public Administration.

Topic: Gestão Pública

Reviewed anonymously in the process of blind peer
Received: 04/04/2021

Approved: 06/06/2021
Antonio Miguel Barros Tenório Varjão dos Santos (iD)

Universidade Federal de Alagoas, Brasil

http://lattes.cnpq.br/8046939920729211

http://orcid.org/0000-0002-0097-6877

antoniomiguel.tvs@gmail.com

Luciana Peixoto Santa Rita (iD

Universidade Federal de Alagoas, Brasil

http://lattes.cnpq.br/9511112631138534

http://orcid.org/0000-0002-6868-9014

lupsantarita@gmail.com
Referencing this:

SANTOS, A. M. B. T. V.; RITA, L. P. S.. O Ministério Público como ombudsman de políticas públicas. Revista Brasileira de Administração Científica, v.12, n.2, p.113-123, 2021. DOI:

http://doi.org/10.6008/CBPC2179-684X.2021.002.0010 


\section{INTRODUÇÃO}

O Ministério Público, nos dizeres do caput do artigo 127 da Constituição da República Federativa do Brasil, promulgada em 05 de outubro de 1988, é instituição permanente, essencial à função jurisdicional do Estado, incumbida da defesa da ordem jurídica, do regime democrático e dos interesses sociais e individuais indisponíveis. O artigo 129 da mesma carta constitucional enumera o extenso rol de atribuições da instituição, dentre as quais se destaca, pela relação com o objeto deste trabalho, o zelo pelo respeito dos Poderes Públicos e dos serviços de relevância pública aos direitos constitucionais e a promoção do inquérito civil e da ação civil pública, para a proteção do patrimônio público e social, do meio ambiente e de outros interesses difusos e coletivos. Em razão destas atribuições, o Ministério Público exerce um grande protagonismo na sociedade brasileira (SADEK, 2000; ARANTES, 2002; KERCHE, 2003).

Esta realidade, contudo, é relativamente recente. Antes do processo de redemocratização do Brasil, iniciado em 1985, os Ministérios Públicos do Brasil eram bastantes diferentes uns dos outros e muito diferentes dos Ministérios Públicos atuais (COMPLOIER, 2015). A primeira Lei Orgânica Nacional do Ministério Público, a Lei Complementar n. 40, de 14 de dezembro de 1981, previa, como únicas atribuições do então órgão do Poder Executivo, a veladura da Constituição e das leis e a promoção da ação penal e da ação civil pública. Embora, em tese, essa descrição sumária de atribuição permitisse uma atuação bastante ampla, na prática "ninguém sabia nem o porquê estava atuando num processo, a não ser na área criminal" (DAL POZZO, 2002).

Inexistia, portanto, o Ministério Público que, atualmente, aparece diariamente nos noticiários, atuando, por exemplo, na regularização de serviços de saúde prestados por hospitais públicos e da qualidade da merenda servida em escolas públicas, na melhoria da estrutura de prédios públicos para torná-los mais acessíveis, no aprimoramento da prestação de serviços de fornecimento de água, energia e telefonia móvel, na fiscalização de exames vestibulares para ingresso em universidades públicas etc.

Formula-se, então, no contexto dos fatos acima descritos, a seguinte pergunta de pesquisa: de que maneira o Ministério Público exerce a função de ombudsman de serviços públicos?

O objetivo geral do presente estudo, portanto, é analisar o exercício da atribuição de controle de políticas públicas pelo Ministério Público. Como objetivos específicos, o presente estudo descreverá a trajetória de empoderamento do Ministério Público brasileiro, identificará as novas atribuições conferidas à instituição, em especial as relativas ao controle de políticas públicas, e examinará os instrumentos disponibilizados ao Parquet para o cumprimento de sua missão.

Com os fins acima expostos, este artigo é composto, além desta introdução e das considerações finais, de outras 3 (três) seções.

Na segunda seção deste trabalho, logo após esta introdução, será examinada a produção científica sobre a trajetória que transformou o Ministério Público, daquele órgão responsável quase que exclusivamente pela promoção da ação penal pública, nesta instituição responsável, entre outras coisas, pela fiscalização de políticas públicas. Neste ponto, será apresentada a figura do ombudsman, instituto de origem 
escandinava, e a Defensoria do Povo, órgão cuja criação foi proposta pela comissão de notáveis designada, em 1985, pelo presidente José Sarney para elaboração do anteprojeto de uma nova Constituição.

Em seguida, na terceira seção, serão examinadas as atribuições constitucionais e legais do atual Ministério Público brasileiro que permitem sua ampla atuação na fiscalização de políticas públicas. Neste ponto, será necessário abordar, também, o próprio significado da expressão 'políticas públicas'.

$\mathrm{Na}$ quarta seção, serão examinados os instrumentos de que dispõe o Ministério Público para cumprir a missão constitucional que Ihe foi outorgada pela Constituição de 1988 para o controle de políticas públicas, como a ação civil pública, o inquérito civil, a recomendação, o compromisso de ajustamento de conduta e a audiência pública.

\section{DISCUSSÃO TEÓRICA}

\section{Transformação do Ministério Público no processo de redemocratização}

Dentre as instituições fundamentais do Estado brasileiro, a que mais se modificou no processo de transição entre a ordem constitucional de 1969 e a ordem constitucional de 1988 foi, sem dúvida, o Ministério Público (CARVALHO et al., 2010).

A Emenda Constitucional n. 1, de 17 de outubro de 1969, que, por sua amplitude em relação à Constituição de 1967 é considerada, verdadeiramente, uma nova Constituição, pouco dizia a respeito do Ministério Público. Dizia, apenas, que a lei federal organizaria o Ministério Público da União; que a lei estadual organizaria o Ministério Público dos Estados; que o chefe do Ministério Público da União seria nomeado pelo Presidente da República, dentre brasileiros com mais de 35 (trinta e cinco) anos de idade, com reputação ilibada e notório saber jurídico e que os seus membros ingressariam na carreira mediante concurso de provas e títulos e que adquiriam estabilidade no cargo após 2 (dois) anos de exercício. Nota-se a ausência, no texto constitucional de 1969, da descrição das atribuições do órgão.

A primeira Lei Orgânica Nacional do Ministério Público, que estabeleceu normas gerais a serem adotadas na organização dos Ministérios Públicos Estaduais, a Lei Complementar n. 40, de 14 de dezembro de 1981, foi, obviamente, muito mais minuciosa que a Constituição de 1969 acerca da estrutura e das atribuições do órgão. Mesmo assim, listava, entre as suas atribuições, apenas, a veladura da observância da Constituição e das leis, a promoção da ação penal pública e a promoção da ação civil pública.

É necessário atentar para o fato de que, nos termos da Constituição de 1969, os Ministérios Públicos Estaduais seriam organizados por lei estadual, e que a Lei Complementa n. 40/81 estabelecia um padrão nacional para os Ministérios Públicos Estaduais que deveriam ser reorganizados, segundo este novo modelo, por leis estaduais que deveriam ser editadas no prazo máximo de 180 (cento e oitenta) dias.

Ocorre que, quando do início do processo de redemocratização do país, em 1985, o que existiam eram Ministérios Públicos Estaduais bastante diferentes entre si (COMPLOIER, 2015). Os membros do Ministério Público do Estado de São Paulo, do Rio Grande do Sul e de Minas Gerais não podiam exercer a advocacia, enquanto os do Rio de Janeiro, podiam. O chefe do Ministério Público do Estado de São Paulo era 
escolhido dentre os membros da carreira, o que não ocorria em alguns outros estados. Também em São Paulo, os vencimentos do Ministério Público eram equiparados aos da magistratura, o que também era diferente em algumas outras unidades da Federação.

Em relação às atribuiç̧̃es do órgão, a mesma heterogeneidade era observada. As atribuições criminais eram bem conhecidas dos membros do Ministério Público e pela sociedade em todo o país, entretanto, "na área cível quase ninguém sabia nem mesmo o que estava fazendo" (DAL POZZO, 2002).

Como a iminência do advento de uma nova ordem constitucional, de onde poderia emergir um modelo nacional de Ministério Público, ocorreu uma mobilização nacional, com a realização de congressos e reuniões, para a criação de uma consciência nacional de Ministério Público que seria apresentada à sociedade e aos congressistas constituintes (COMPLOIER, 2015).

Paralelamente a isto, o Presidente José Sarney havia nomeado, em 18 de julho de 1985, uma comissão de notáveis, presidida pelo professor Afonso Arinos de Melo Franco, para elaborar um anteprojeto para a nova Constituição. Embora o anteprojeto elaborado pela Comissão Provisória de Estudos Constitucionais não tenha servido de base para a elaboração da nova Constituição, muitas das suas disposições foram aproveitadas pelo Congresso Nacional Constituinte. Dentre as propostas da comissão de notáveis, merece destaque, para o objeto deste estudo, a insculpida no art. 56 do anteprojeto por ela elaborado, que versava sobre a criação de uma nova instituição - a Defensoria do Povo:

Art. 56. É criado o defensor do povo, incumbido, na forma de lei complementar, de zelar pelo efetivo respeito dos poderes do Estado aos direitos assegurados nesta Constituição, apurando abusos e omissões de qualquer autoridade e indicando aos órgãos competentes as medidas necessárias à sua correção ou punição.

$\S 1^{\circ} \mathrm{O}$ defensor do povo poderá promover a responsabilidade da autoridade requisitada no caso de omissão abusiva na adoção das providências requeridas.

$\S 2^{\circ}$ Lei complementar disporá sobre a competência, a organização e o funcionamento da Defensoria do Povo, observados os seguintes princípios:

I - o defensor do povo é escolhido, em eleição secreta, pela maioria absoluta dos membros da Câmara dos Deputados, entre candidatos indicados pela sociedade civil e de notório respeito público e reputação ilibada, com mandato renovável de cinco anos;

II - são atribuídos ao defensor do povo a inviolabilidade, os impedimentos, as prerrogativas processuais dos membros do Congresso Nacional e os vencimentos dos ministros do Supremo Tribunal Federal;

III - as Constituições Estaduais poderão instituir a Defensoria do Povo, de conformidade com os princípios constantes deste artigo.

O professor Tácito (1988) informa que a comissão de notáveis se inspirou, para elaboração desta proposta, no instituto escandinavo do ombudsman, existente na Suécia desde 1809, na Finlândia desde 1919, na Noruega desde 1952, na Dinamarca desde 1954 e na Nova Zelândia, de onde migrou para outros países anglo-saxões, desde 1961. Nestes países, o ombudsman é um comissário eleito pelo Parlamento para receber queixas e realizar inspeções espontâneas nos órgãos públicos, a fim de conter eventuais abusos dos agentes estatais. Especificamente na Suécia, o ombudsman surgiu originalmente para equilibrar, em favor do Parlamento, os poderes de fiscalização de funcionários públicos, já exercidos por um delegado do Rei, o justitienkansler (GUALAZZI, 1991). 
No Brasil, antes do anteprojeto da comissão de notáveis, existiram outras propostas no âmbito federal, todas frustradas, objetivando a criação de órgãos, cargos ou instituições inspiradas no ombudsman escandinavo, como a Procuradoria-Geral do Povo, a Procuradoria-Geral do Poder Legislativo, a Procuradoria Popular, o Ouvidor-Geral, o Promotor-Geral da Nação, todos com atribuição de receber denúncias e fiscalizar a atuação de servidores públicos e a qualidade dos serviços públicos. No âmbito local, o Município de Curitiba criou, no ano de 1986, uma Ouvidoria Municipal e o Município de São José dos Campos criou, no ano de 1984, uma Corregedoria Administrativa e um cargo de Defensor do Interesse Público, todos inspirados no instituto de origem sueca (TÁCITO, 1988).

A proposta da comissão de notáveis de criação da Defensoria do Povo também restou infrutífera, entretanto, um movimento de promotores de Justiça que acompanhava os trabalhos do Congresso Nacional Constituinte, tanto junto aos congressistas quanto junto à sociedade, acabou conseguindo incorporar ao Ministério Público as atribuições que a comissão de notáveis gostaria de entregar ao órgão que não chegou a ser criado (MAZZILLI, 2011).

Dal Pozzo (2002), um dos promotores de Justiça que atuou neste processo de transformação do Ministério Público, em entrevista concedida ao procurador de Justiça Ricardo Vaz Seelig, afirmou que, nos trabalhos do Congresso Nacional Constituinte, acabou se tornando prática corriqueira, sempre que se percebia uma falha no sistema de controle do Estado em processo de criação, se atribuía a solução ao Ministério Público.

Nós começamos a fazer campanha, nós começamos a ir aos jornais, a dizer 'o promotor é o defensor do povo', porque nós sabíamos que havia uma aspiração para criar talvez um ombudsman fora da instituição. Nós começamos a criar um movimento de valorização do Ministério Público (...) brincávamos que àquela época se dizia: 'Vai reclamar para o Bispo!'... e nós queríamos ser esse 'Bispo'. (DAL POZZO, 2002)

Foi neste contexto e com esta trajetória que o Ministério Público adquiriu as atribuições hoje elencadas no artigo 129 da Constituição da República, dentre as quais se destaca, pela relação com o objeto desta pesquisa, as previstas no inciso II para 'zelar pelo efetivo respeito dos Poderes Públicos e dos serviços de relevância pública aos direitos assegurados nesta Constituição, promovendo as medidas necessárias à sua garantia' e no inciso III para 'promover o inquérito civil e a ação civil pública, para a proteção do patrimônio público e social, do meio ambiente e de outros interesses difusos e coletivos'.

\section{Atuais atribuições do Ministério Público para controle de políticas públicas}

Diferentemente da Constituição Brasileira de 1969 e de todas as demais que a antecederam, as de 1824, 1891, 1934, 1937, 1946 e 1967, a Constituição da República Federativa do Brasil de 1988 tratou do Ministério Público de forma bastante detalhada para um texto constitucional e conferiu à instituição atribuições bastante relevantes, que ensejaram o exercício de um enorme protagonismo (SADEK, 2000; ARANTES, 2002; KERCHE, 2003).

Em vez de órgão do Poder Executivo, como figurava em todas as Constituições anteriores, o Ministério Público foi definido, pela atual Carta Política, como instituição permanente, essencial à função jurisdicional do Estado, incumbida da defesa da ordem jurídica, do regime democrático e dos interesses 
sociais e individuais indisponíveis, sem vínculo de pertencimento ou subordinação com os Poderes Executivo, Legislativo e Judiciário, possuindo autonomia funcional, administrativa, financeira e orçamentária. A Constituição de 1988, em seu artigo 2ำ, não elencou o Ministério Público entre os Poderes do Estado, mas indubitavelmente conferiu à instituição garantias idênticas às dos Poderes (MAZZILLI, 2005).

As atribuições da instituição também constam, atualmente, no texto constitucional, em um rol exemplificativo bastante extenso:

Art. 129. São funções institucionais do Ministério Público:

I - promover, privativamente, a ação penal pública, na forma da lei;

II - zelar pelo efetivo respeito dos Poderes Públicos e dos serviços de relevância pública aos direitos assegurados nesta Constituição, promovendo as medidas necessárias à sua garantia;

III - promover o inquérito civil e a ação civil pública, para a proteção do patrimônio público e social, do meio ambiente e de outros interesses difusos e coletivos;

IV - promover a ação de inconstitucionalidade ou representação para fins de intervenção da União e dos Estados, nos casos previstos nesta Constituição;

$\mathrm{V}$ - defender judicialmente os direitos e interesses das populações indígenas;

VI - expedir notificações nos procedimentos administrativos de sua competência, requisitando informações e documentos para instruí-los, na forma da lei complementar respectiva;

VII - exercer o controle externo da atividade policial, na forma da lei complementar mencionada no artigo anterior;

VIII - requisitar diligências investigatórias e a instauração de inquérito policial, indicados os fundamentos jurídicos de suas manifestações processuais;

IX - exercer outras funções que Ihe forem conferidas, desde que compatíveis com sua finalidade, sendo-lhe vedada a representação judicial e a consultoria jurídica de entidades públicas.

Dentre as atribuições da instituição, destacam-se, por sua relação com o objeto deste trabalho, qual seja, o papel do Ministério Público como ombudsman de políticas públicas, as atribuições previstas nos incisos II e III do artigo 129 da Constituição Federal para zeladoria do efetivo respeito dos serviços de relevância pública aos direitos constitucionais e para promoção do inquérito civil e da ação civil pública para proteção do patrimônio público e social e de outros interesses difusos e coletivos.

Inicialmente, nota-se que a redação do inciso II do artigo 129 da atual Constituição Federal é praticamente idêntica à redação do caput do artigo 56 do anteprojeto elaborado pela Comissão Provisória de Estudos Constitucionais, nomeada pelo Presidente José Sarney em 18 de julho de 1985, que pretendia a criação da Defensoria do Povo para o exercício desta atribuição que acabou entregue, pelo Congresso Nacional Constituinte, ao Ministério Público.

Ocorre que, diferentemente do ombudsman escandinavo, o Ministério Público brasileiro, com funções singulares em relação a seus congêneres do mundo inteiro (RODRIGUES, 2007), além de receber reclamações de cidadãos acerca de infrações dos Poderes Públicos e dos serviços de relevância pública aos direitos constitucionais e de investigá-las, tem a atribuição de realizar a persecução, administrativa, cível e criminal, dos responsáveis em juízo (MAZZILLI, 1989).

Uma leitura apressada do inciso II do art. 129 da Constituição Federal poderia levar ao entendimento 
manifestamente equivocado de que o Ministério Público teria a função de zelar para que os Poderes Públicos e os serviços de relevância pública sejam respeitados, contudo, o que o Constituinte de 1988 diz, neste dispositivo, é que o Ministério Público tem a função de zelar para que os Poderes Públicos e os serviços de relevância pública respeitem os direitos assegurados na Constituição.

Considerando-se as numerosas definições de políticas públicas apresentadas por Souza (2006), sobretudo a de Dye, que define as políticas públicas como aquilo que o governo faz ou deixa de fazer, percebe-se que a atribuição ministerial insculpida no inciso II do artigo 129 da Constituição Federal poderia ser traduzida em controle de políticas públicas:

Não existe uma única, nem melhor, definição sobre o que seja política pública. Mead (1995) a define como um campo dentro do estudo da política que analisa o governo à luz de grandes questões públicas. Lynn (1980) a define como um conjunto específico de ações do governo que irão produzir efeitos específicos. Peters (1986) segue o mesmo veio: política pública é a soma das atividades dos governos, que agem diretamente ou através de delegação, e que influenciam a vida dos cidadãos. Dye (1984) sintetiza a definição de política pública como 'o que o governo escolhe fazer ou não fazer'.

No campo teórico das políticas públicas, é bastante conhecido o método de análise das políticas públicas em ciclos constituídos, segundo Frey (2000), por 5 (cinco) fases: a primeira, da percepção do problema; a segunda, de inclusão do problema na agenda; a terceira, da elaboração de políticas para solução do problema; a quarta, de execução da política; e, a quinta, de avaliação e correção do que foi executado. Para Coelho et al. (2013), a atuação do Ministério Público sobre as políticas públicas ocorreria nas duas primeiras etapas do policy cycle, de percepção do problema e de sua inclusão na agenda pública.

Várias são as campanhas que, por todo o Brasil, o Ministério Público vem realizando tanto de maneira isolada quanto em parceria com instituições da sociedade civil, no intuito de tornar visíveis determinados problemas, iniciando ou intensificando o seu debate. (COELHO et al., 2013)

O entendimento de Coelho et al. (2013), contudo, praticamente equipara o Ministério Público, no exercício da atribuição prevista no inciso II do artigo 129 da Constituição Federal, aos movimentos sociais reivindicativos da segunda metade do século XX, no formato descrito por Alonso (2009) e Gohn (2011). A instituição, evidentemente, não é um movimento social.

Não muito diferente é a posição de Costa (2017), que aparentemente centraliza a atuação do Ministério Público na fase de execução das políticas públicas, valendo-se, contudo, de argumentos que também assemelham a instituição a um movimento social:

Como superego da sociedade, o Ministério Público é responsável pela implementação e acompanhamento de políticas públicas, sendo no mínimo contraditório sustentar que pode o Promotor de Justiça deixar de atuar porque não há lesão imediata a bens jurídicos ou pelo fato de que alguns procedimentos não possuem objeto claro e definido. Ao contrário, os Membros do Ministério Público devem assumir verdadeiramente a condição de agentes juspolíticos e passarem a acompanhar os interesses mais lídimos da sociedade, suas reais prioridades e carências mais profundas. (COSTA, 2017)

A Constituição Federal não restringe a atuação do Ministério Público, no exercício da atribuição prevista no inciso II do artigo 129, a nenhuma fase específica do policy cycle, devendo a instituição atuar em qualquer fase diante da suspeita de desrespeito, tanto por ação quanto por omissão, aos direitos assegurados na Carta Política. Esta atuação de dará mediante o manuseio de instrumentos previstos na 
própria Constituição, em leis e em resoluções do Conselho Nacional do Ministério Públicos e dos próprios Ministérios Públicos. A ação civil pública e o inquérito civil, mencionados no inciso III do artigo 129, constituem instrumentos, e não exatamente atribuições e, por isso, serão abordados no capítulo subsequente.

\section{Dos instrumentos disponíveis ao Ministério Público para cumprimento de suas atribuições de ombudsman}

A própria Constituição Federal prevê alguns dos instrumentos necessários para que o Ministério Público exerça as atribuições de ombudsman de políticas públicas que Ihe foram confiadas pelo Congresso Nacional Constituinte de 1988, como a ação civil pública e o inquérito civil, destinados à proteção do patrimônio público e social, do meio ambiente e de outros interesses difusos e coletivos. Outros instrumentos estão previstos em normas infraconstitucionais, como o compromisso de ajustamento de conduta, previsto na Lei n. 7.347, de 24 de julho de 1985, a recomendação e a audiência pública, previstas na Lei n. 8.625, de 12 de fevereiro de 1993.

A ação civil pública, mencionada no inciso III do artigo 129 da Constituição de 1988, é um instituto jurídico pré-constitucional, já havendo menção a ela na primeira Lei Orgânica Nacional do Ministério Público, a Lei Complementar n. 40, de 14 de dezembro de 1981. Figueiredo (2013) sustenta que suas origens remontam às chamadas class actions do direito americano. A ação civil pública foi minuciosamente regulamentada pela Lei n. 7.347, de 24 de julho de 1985, portanto, antes da promulgação da atual Constituição Brasileira e antes mesmo do início dos trabalhos do Congresso Nacional Constituinte, mas já durante o processo de redemocratização do país. A referida norma, que sofreu sucessivas modificações desde sua promulgação, prevê a ação civil pública para a defesa do meio ambiente, do consumidor, dos valores artístico, estético, histórico, turístico e paisagístico, da ordem econômica, da ordem urbanística, da honra e dignidade de grupos raciais, étnicos ou religiosos, do patrimônio público e social, bem como de qualquer outro direito difuso e coletivo.

O artigo 5 da lei em questão atribui ao Ministério Público, sem exclusividade, a titularidade da ação civil pública, que também é atribuída à Defensoria Pública, à União, aos Estados, ao Distrito Federal e aos Municípios, às autarquias, fundações, empresas públicas e sociedades de economia mista e às associações constituídas há mais de 1 (um) ano e que inclua, entre as suas finalidades institucionais, a defesa de direitos difusos e coletivos. O Ministério Público, contudo, apesar de não ser o único legitimado para a ação, deverá intervir em todas elas, mesmo nas que não foram propostas pela instituição, como fiscal da ordem jurídica. De uma ação civil pública pode resultar uma condenação a pagamento de quantia em dinheiro, uma obrigação de fazer e/ou uma obrigação de não fazer.

O inquérito civil, também mencionado no inciso III do artigo 129 da Constituição Federal, é um procedimento extrajudicial que tem como finalidade a apuração de um fato que pode ensejar a tutela de direitos e interesses a cargo do Parquet. O inquérito civil, presidido por um membro do Ministério Público, instrumentaliza a investigação de um ilícito civil-público da mesma forma que o inquérito policial, presidido por um delegado de Polícia Civil, investiga um ilícito criminal. Diferentemente da ação civil pública, o 
inquérito civil, que também foi, superficialmente, disciplinado pela Lei n. 7.347, de 24 de julho de 1985, é um instrumento exclusivo do Ministério Público. $O$ inquérito civil está detalhadamente regulamentado pela resolução n. 23, de 17 de setembro de 2007, pelo Conselho Nacional do Ministério Público.

No bojo de um inquérito civil, ou fora dele, o Ministério Público pode firmar compromissos de ajustamento de sua conduta às exigências legais, que, caso descumprido, pode ser exigido judicialmente. 0 compromisso ou termo de ajustamento de conduta também foi, superficialmente, regulamentado pela Lei n. 7.347, de 24 de julho de 1985, que o disponibiliza para os demais órgãos públicos que tem legitimidade ativa para ação civil pública, portanto, ele não é um instrumento exclusivo do Ministério Público.

Para o cumprimento da atribuição de ombudsman de políticas públicas, o Ministério Público dispõe, ainda, do instrumento da recomendação, que não é mencionado na Constituição Federal, nem na Lei $\mathrm{n}$. 7.347, de 24 de julho de 1985, a Lei da Ação Civil Pública, tendo sido mencionada na atual Lei Orgânica Nacional do Ministério Público, a Lei n. 8.625, de 12 de fevereiro de 1993. Sua regulamentação encontra-se na resolução n. 164, de 28 de março de 2017, do Conselho Nacional do Ministério Público, que, em seu artigo 1ㅇ, define a recomendação como:

(...) instrumento de atuação extrajudicial do Ministério Público por intermédio do qual este expõe, em ato formal, razões fáticas e jurídicas sobre determinada questão, com o objetivo de persuadir o destinatário a praticar ou deixar de praticar determinados atos em benefício da melhoria dos serviços públicos e de relevância pública ou do respeito aos interesses, direitos e bens defendidos pela instituição, atuando, assim, como instrumento de prevenção de responsabilidades ou correção de condutas.

A recomendação, como o nome sugere, não tem caráter coercitivo, pois visa persuadir, pela exposição dos fatos e do direito, o destinatário a praticar um ato ou dele se abster. Caso a recomendação não seja acatada, não seja cumprida ou não seja respondida, o Ministério Pública adotará as medidas cabíveis, provavelmente o ajuizamento de ação civil pública, para obter o comportamento pretendido.

Outro instrumento de que dispõe o Ministério Público para o controle de políticas públicas é a audiência pública, prevista no art. 27, parágrafo único, inciso IV, da Lei Orgânica Nacional do Ministério Público, e regulamentada pela resolução n. 82, de 29 de fevereiro de 2012, do Conselho Nacional do Ministério Público, e que tem a função de auxiliar o Ministério Público na resolução dos procedimentos sobre sua incumbência, identificação de demandas sociais, elaboração e execução de planos de ação e projetos estratégicos e para prestação de contas à sociedade.

\section{CONCLUSÕES}

Ao logo deste trabalho, foi examinada a trajetória que levou o Ministério Público, de um órgão responsável quase que exclusivamente pela promoção da ação penal, a uma instituição permanente, essencial a função jurisdicional do Estado, incumbida da defesa da ordem jurídica, do regime democrático e dos interesses sociais e individuais indisponíveis. Neste processo de transformação, o Ministério Público incorporou as atribuições que a comissão de notáveis presidida por Afonso Arinos gostaria de atribuir a um órgão novo, a Defensoria do Povo, inspirado no ombudsman dos países escandinavos e que não chegou a ser criado. 
Viu-se que a Defensoria do Povo teria atribuição para zelar para que os Poderes Públicos e os serviços de relevância pública respeitassem os direitos garantidos na Constituição, e que essa mesma atribuição foi entregue ao Ministério Público, que, atualmente, exerce um controle externo das políticas públicas nas fases de identificação do problema, da inclusão do problema na agenda pública, da formulação da política pública, de sua execução e de sua avaliação.

Para o cumprimento desta atribuição de controle de políticas públicas, o Ministério Público dispõe de instrumentos, alguns mencionados na própria Constituição, como a ação civil pública e o inquérito civil, e outros previstos em normas infraconstitucionais, como o compromisso de ajustamento de conduta, a recomendação e a audiência pública.

A relevância do Ministério Público no ciclo de políticas públicas é patente, contudo, sua efetividade precisa ser constantemente verificada por pesquisas da Administração Pública, da Ciência Política e, obviamente, do Direito.

Como sugestão para estudos futuros, recomenda-se a medição do nível de persuasão das recomendações expedidas pelo Ministério Público a fim de verificar até que ponto elas constituem um instrumento eficaz de controle de políticas públicas e a realização de estudos de casos a fim de verificar, em casos concretos e específicos, como o Ministério Público interfere no ciclo de políticas públicas.

\section{REFERÊNCIAS}

ALONSO, Â.. As teorias dos movimentos sociais: um balanço do debate. Lua Nova: Revista de Cultura e Política, São Paulo, n.76, p.49-86, 2009.

ARANTES, R. B.. Ministério Público e política no Brasil. São Paulo: Sumaré, 2002.

BRASIL. Constituição (1967). Constituição do Brasil. Emenda Constitucional n.1, de 17 de outubro de 1969. Brasília: DOU, 1969.

BRASIL. Constituição (1988). Constituição da República Federativa do Brasil, de 05 de outubro de 1988. Brasília: DOU, 1988.

BRASIL. Lei Complementar $\mathbf{n} . \mathbf{4 0}$, de $\mathbf{1 4}$ de setembro de 1981. Estabelece normas gerais a serem adotadas na organização do Ministério Público estadual. Brasília: DOU, 1981.

BRASIL. Lei n.7.347, de 24 de julho de 1985. Disciplina a ação civil pública de responsabilidade por danos causados ao meio-ambiente, ao consumidor, a bens e direitos de valor artístico, estético, histórico, turístico e paisagístico e dá outras providências. Brasília: DOU, 1985.

BRASIL. Lei n.8.625, de 12 de fevereiro de 1993. Institui a Lei Orgânica Nacional do Ministério Público, dispõe sobre normas gerais para a organização do Ministério Público dos Estados e dá outras providências. Brasília: DOU, 1993.

BRASIL. Conselho Nacional do Ministério Público. Resolução n.23, de 17 de setembro de 2007. Brasília: CNMP, 2007.
BRASIL. Conselho Nacional do Ministério Público. Resolução n.82, de 29 de fevereiro de 2012. Brasília: CNMP, 2012.

BRASIL. Conselho Nacional do Ministério Público. Resolução n.164, de 28 de março de 2017. Brasília: CNMP, 2017.

CARVALHO, E.; LEITÃO, N.. O novo desenho institucional do Ministério Público e o processo de judicialização da política. Revista Direito GV, São Paulo, v.6, n.2, p.399-421, 2010.

COELHO, S. R.; KOZICKI, K.. O Ministério Público e as políticas públicas: definindo a agenda ou implementando as soluções?. Revista AJURIS, Porto Alegre, v.40, n.130, p.373394, 2013.

COMPLOIER, M.. O Ministério Público e Assembleia Nacional Constituinte: as origens de um texto inovador. Meritum, Belo Horizonte, v.10, n.1, p.275-305, 2015.

COSTA, R. O.. Do Ministério Público como Superego da Sociedade: design institucional e legitimidade na atuação judicial e extrajudicial. Sequência, Florianópolis, n.76, p.115130, 2017.

DAL POZZO, A. A. F.. O Ministério Público do Estado do Rio Grande do Sul e a Assembleia Constituinte. Depoimento concedido ao Procurador de Justiça Ricardo Vaz Seelig. Memorial do Ministério Público do Rio Grande do Sul, 2002.

FIGUEIREDO, L. V.. Lições de Direito Constitucional. Rio de Janeiro: Forense, 2013.

FREY, K.. Políticas públicas: um debate conceitual e reflexões referentes à prática da análise de políticas públicas no Brasil. 
Planejamento e Políticas Públicas, Rio de Janeiro, n.21, p.211-259, 2000.

GOHN, M. G.. Movimentos sociais na contemporaneidade. Revista Brasileira de Educação, Rio de Janeiro, v.16, n.47, p.333-361, 2011.

GUALAZZI, E. L. B.. Controle administrativo e 'Ombudsman'. Revista da Faculdade de Direito, São Paulo, v.86, p.144-163, 1991.

MAZZILLI, H. N.. O Ministério Público e o acesso à justiça. Revista Justitia, São Paulo, v.146, p.68-78, 1989.

MAZZILLI, H. N.. Ministério Público. 3 ed. São Paulo: Damásio de Jesus, 2005.

MAZZILLI, H. N.. Entrevista concedida à Comissão do Memorial do Ministério Público do Estado de São Paulo (Dr. Alexandre Rocha Almeida de Moraes, Dra. leda Casseb Casagrande Bignardi, Dr. Ruy Alberto Gatto e Dr. Walter
Paulo Sabella). Memorial do Ministério Público do Estado de São Paulo, 2011.

KERCHE, F.. O Ministério Público no Brasil: autonomia, organização e atribuições. Tese (Doutorado em Ciência Política) - Universidade de São Paulo, São Paulo, 2003.

RODRIGUES, G.. Breve cotejo sobre o papel do Ombudsman da saúde norueguês e a atuação do Ministério Público em defesa do direito à saúde no Brasil. Revista de Direito Sanitário, São Paulo, v.8, n.2, p.82-104, 2007.

SADEK, M. T.. Cidadania e ministério público. In: SADEK, M. T.. Justiça e cidadania no Brasil. São Paulo: Sumaré, 2000.

SOUZA, C.. Políticas públicas: uma revisão de literatura. Sociologias, Porto Alegre, v.8, n.16, p.20-45, 2006.

TÁCITO, C.. Ombusdman: o defensor do povo. Revista de Direito Administrativo, Rio de Janeiro, n.171, p.15-26, 1988.

A CBPC - Companhia Brasileira de Produção Científica (CNPJ: 11.221.422/0001-03) detém os direitos materiais desta publicação. Os direitos referem-se à publicação do trabalho em qualquer parte do mundo, incluindo os direitos às renovações, expansões e disseminações da contribuição, bem como outros direitos subsidiários. Todos os trabalhos publicados eletronicamente poderão posteriormente ser publicados em coletâneas impressas sob coordenação da Sustenere Publishing, da Companhia Brasileira de Produção Científica e seus parceiros autorizados. Os (as) autores (as) preservam os direitos autorais, mas não têm permissão para a publicação da contribuição em outro meio, impresso ou digital, em português ou em tradução. 